Journal of Hard Tissue Biology 22[4] (2013)419-424

\title{
Original
}

\section{Biofilm Bormation on Titanium and Hydroxyapatite Surface using Artificial Mouth System}

\author{
Eiji Yoshida ${ }^{1)}$, Susumu Imai ${ }^{2)}$, Nobuhiro Hanada ${ }^{2)}$ and Tohru Hayakawa ${ }^{1)}$ \\ 1) Department of Dental Engineering, Tsurumi University School of Dental Medicine, Yokohama, Japan \\ ${ }^{2)}$ Department of Translational Research, Tsurumi University School of Dental Medicine, Yokohama, Japan \\ (Accepted for publication, July 3, 2013)
}

\begin{abstract}
Biofilm formation in the oral cavity is postulated to cause oral diseases such as dental caries, periodontal diseases, and peri-implantitis etc. Recently, an artificial mouth system (AMS) was developed to study oral biofilm formation on dental materials in vitro by simulating the human oral environment. The purpose of this study was to monitor the biofilm formation on titanium (Ti) and hydroxyapatite (HA) using AMS and to evaluate the biofilm morphology by scanning electron microscopy (SEM). As bacterial strains, Streptococcus mutans (S.mutans) and Streptococcus sobrinus (S. sobrinus) were employed. The number of bacterial cells on each specimen was evaluated after 5 and 18 hours assays. The number of $S$. mutans cells after 18 hours was significantly higher than after 5 hours $(\mathrm{p}<0.05)$. No significant differences existed between Ti and HA specimens for both $S$. mutans and $S$. sobrinus cells in each assay period. The 18 hours assay specimens provided a significantly higher amount of water-insoluble glucan (WIG) by $S$. mutans than 5 hours specimens $(\mathrm{p}<0.05)$. There were no significant differences between Ti and HA in the amount of WIG in each assay period. On SEM observation, biofilm formation of $S$. mutants and $S$. sobrinus was recognized on the HA specimen surface and no distinct differences were recognized. Higher magnification observation revealed the formation of pores with a diameter of approximately $5 \mu \mathrm{m}$. This was due to the $\mathrm{pH}$ decrease during biofilm formation. Ti surface could not be influenced by the decrease of $\mathrm{pH}$. This was confirmed by acid etching of HA and Ti. Pores were also formed by acid etching on enamel but not on Ti. It is suggested that the formation of such pores is related with caries formation. In conclusion, biofilm formation on HA and Ti could be monitored using AMS.
\end{abstract}

Key words: Artificial mouth system, Biofilm, Streptococcus mutans, Streptococcus sobrinus, Hydroxyapatite, Titanium

\section{Introduction}

Dental caries is one of the most prevalent infectious diseases in humans. Bacteria that attach to and accumulate on the teeth are responsible for initiating dental caries. Dental plaque biofilm is the deposit of proteins, cell-free enzymes, and bacteria embedded in exopolysaccharides that adhere firmly to the tooth surface, and dental caries is now recognized as a biofilm-dependent oral disease, and prevention of the biofilm formation is a useful to protect against dental caries.

In addition to dental caries, biofilm formation in the oral cavity is postulated to cause periodontal diseases. Sometimes biofilm formation causes denture-induced stomatitis and peri-implantitis after denture setting or implant placement, respectively. Biofilm consists of a complex of attached bacterial and salivary macromolecules, and forms on not only teeth and the mucosal

Correspondence to: Dr. Eiji Yoshida, Department of Dental Engineering, Tsurumi University School of Dental Medicine, 2-1-3 Tsurumi, Tsurumiku, Yokohama, 230-8501 Japan; Tel.: +81-45-580-8369; Fax: +81-45573-9599; E-mail: yoshida-e@tsurumi-u.ac.jp surface but also the surface of metal or ceramic prostheses, orthodontic brackets, resin restoratives and Ti implants ${ }^{1-3)}$.

Some antibacterial resins or surface modifications for titanium (Ti) implants have been introduced and their antibacterial activities evaluated. However, there are few studies of biofilm formation on different substances, for example, enamel or Ti implants.

Recently, an artificial mouth system (AMS) was developed to study oral biofilm formation on dental materials in vitro by simulating the human oral environment ${ }^{4,5}$. Using the AMS, a study model was established to provide a better understanding of how the surface properties of dental materials could influence biofilm adherence and growth. Ono et al. and Ikeda et al. ${ }^{6,7)}$ investigated biofilm formation on various resin composites using AMS and found that the surface roughness and composition of resin composites influenced biofilm adherence. A primary artificial secondary caries model was also established using AMS ${ }^{8)}$.

The purpose of this study was to monitor biofilm formation on Ti and hydroxyapatite (HA) using AMS and to evaluate the biofilm morphology by scanning electron microscopy (SEM). As 


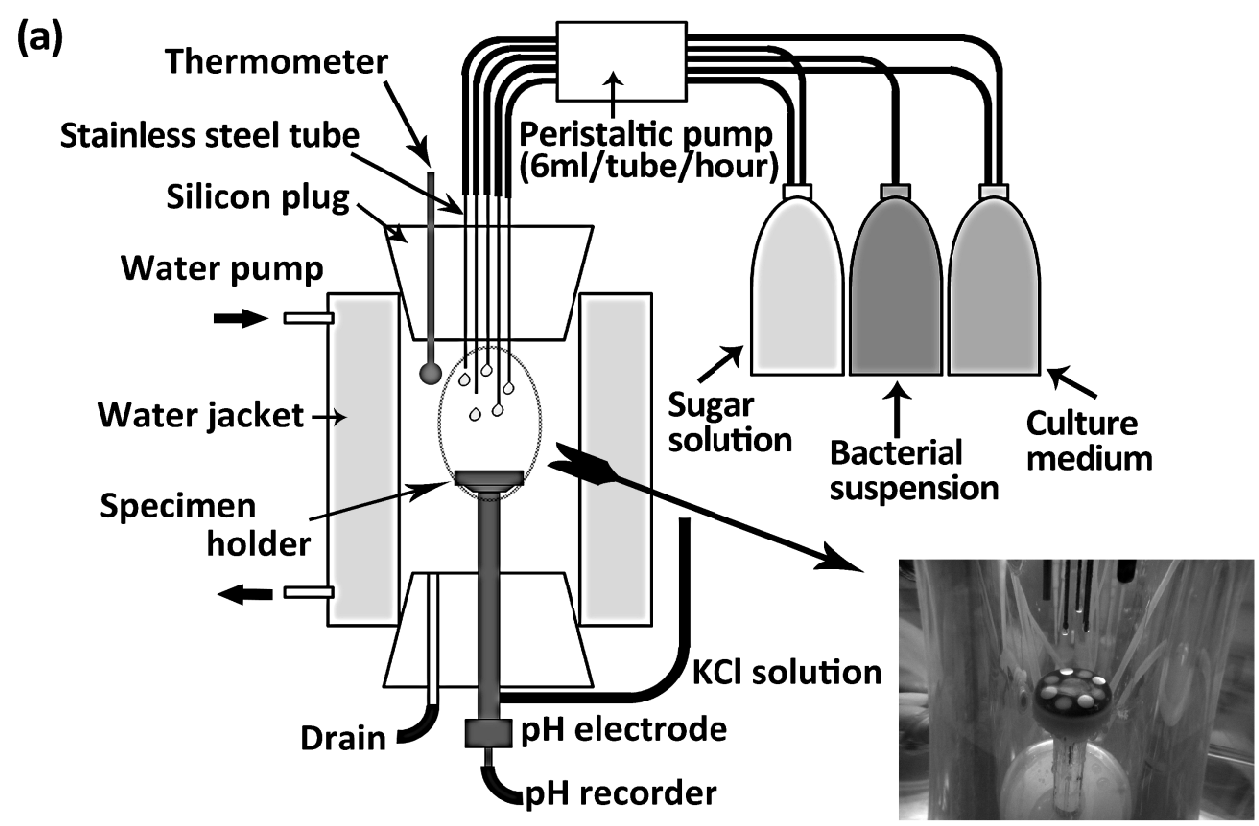

(b)
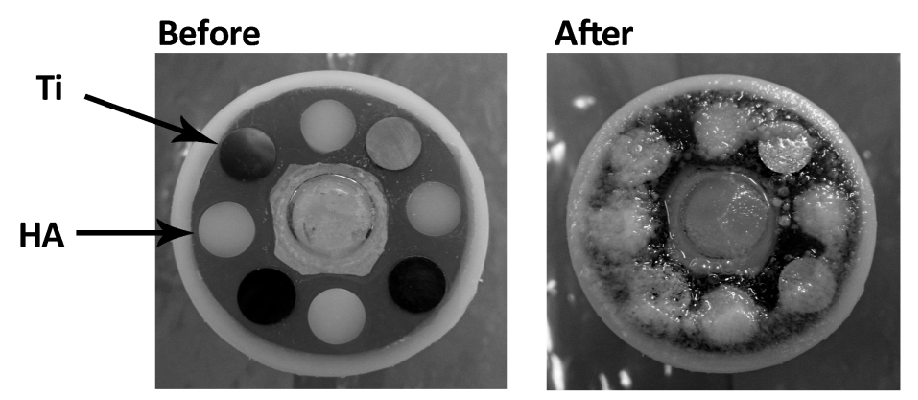

Figure 1. Schematic diagram of AMS (a). Images of specimens before (left) and 18 hours (right) after biofilm formation (b).

bacterial strains, Streptococcus mutans and Streptococcus sobrinus were employed because they are the major pathogenic bacteria associated with dental biofilms ${ }^{9}$.

\section{Materials and Methods}

\section{Specimen}

Machined commercially pure wrought Ti disks $(\mathrm{Ra}=$ approximately $0.9 \mu \mathrm{m}$, Japan Industrial Specification H 4600, 99.9 mass \%; Furuuchi Chemical Corp., Tokyo, Japan) with a diameter of $5 \mathrm{~mm}$, and a polished high sintered HA pellet $(\mathrm{Ra}=$ approximately $0.24 \mu \mathrm{m}$, CELLYARD HA pellet; PENTAX Corp., Tokyo, Japan) with a diameter of $5 \mathrm{~mm}$ were used in this study.

\section{Contact angle measurements}

The contact angle of each specimen surface with respect to double-distilled water was measured using a contact angle meter (CA-P; Kyowa Interface Science Co. Ltd., Tokyo, Japan). The volume of water drops was maintained at $2 \mu \mathrm{L}$ and five measurements for $5 \mathrm{sec}$ each were made for Ti and HA surfaces. Measurements were performed at the same room temperature and humidity

\section{Preparation of bacterial suspension}

Streptococcus mutans (S. mutans) ATCC 25175 and Sterptococcus sobrinus (S. sobrinus) ATCC 33478 were used in this study. A suspension of $S$. mutans and $S$. sobrinus in PBS (phosphate-buffered saline, $\mathrm{pH} 7.2$ ) at $\mathrm{OD}_{500}=2$ (approximately 2 $\times 10^{7}$ colony-forming units $/ \mathrm{ml}$ ) was prepared from 16 hours fresh culture in TS (Bacto Tryptic Soy Broth; Becton Dickinson, Sparks, MD, USA) after washing with PBS and was stored at $4{ }^{\circ} \mathrm{C}$. For growth in the AMS, a solution of TS without dextrose (Becton Dickinson) but with $1 \%$ sucrose was used.

\section{Biofilm formation in the AMS}

Schematic diagram of the AMS is shown in Fig. 1. The AMS consisted of three identical columnar artificial mouths, a thermostatic incubator, multiple $\mathrm{pH}$ meter, peristaltic pump, and cooling stirrer (Fig. 1a). The artificial mouth $(60 \mathrm{~mm}$ in diameter, $140 \mathrm{~mm}$ in height) and surrounding water jacket $(140 \mathrm{~mm}$ in diameter) were made from transparent vinyl chloride. Warm water 
(a) S. mutans

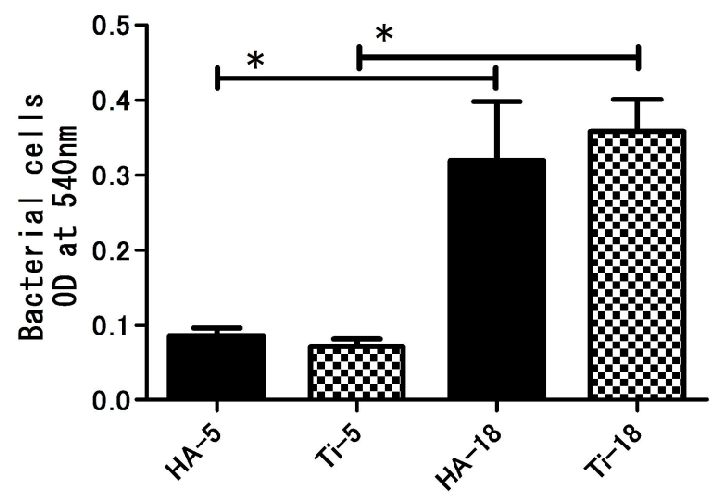

(b) S. sobrinus

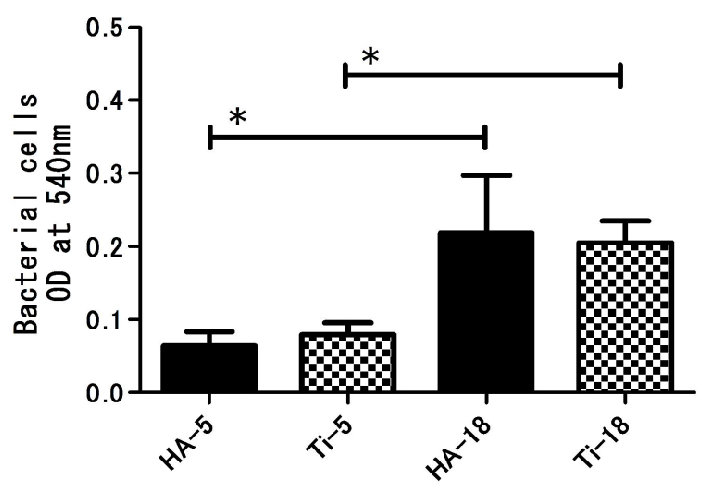

Figure 2. Number of bacterial cells on each specimen with different assay periods ( 5 and 18 hours). Bars represent means $\pm \mathrm{SD},{ }^{*} \mathrm{P}<0.05$. a: $S$. mutans, b: S. sobrinus.

was circulated using the thermostatic incubator (Taitech, Saitama, Japan) to maintain the temperature of the artificial mouths at 37 ${ }^{\circ} \mathrm{C}$. A pH electrode with a flat bulb $(9 \mathrm{~mm}$ diameter; TOA-DKK, Tokyo, Japan) was set upside down in the center of the artificial mouth with a silicon plug.

Eight specimens were arranged on the flat surface of a special Teflon holder (28mm diameter) around the bulb of the electrode. Another silicon plug with five stainless steel tubes and a thermometer was set in the upper part of the artificial mouth to constantly supply TS medium supplemented with sucrose, PBS and bacterial cell suspension with a peristaltic pump (Furue Science, Tokyo, Japan). The cell suspension $\left(\mathrm{OD}_{500}=2.0\right)$ was maintained at a low temperature with gentle stirring using a cooling stirrer (Iwaki Glass, Tokyo, Japan) during the experiment. Changes in $\mathrm{pH}$ underneath the artificial biofilm were continuously monitored with a multiple $\mathrm{pH}$ recorder (TOA-DKK). All procedures were conducted under aseptic conditions.

\section{Evaluation of quantity of artificial biofilm}

After stopping the operation of the AMS, the biofilm formed on each specimen and the flat bulb was carefully removed with silicon scraper before being immersed in a $0.5 \mathrm{~N} \mathrm{NaOH}$ solution to resolve the water-insoluble glucan (WIG) on ice (Fig. 1b). This was followed by centrifugation $(3,000 \mathrm{rpm}, 20 \mathrm{~min})$ to separate the bacterial cells from the WIG. Bacterial cells were re-suspended in PBS and turbidity at $500 \mathrm{~nm}$ was measured. In addition, the amount of WIG in $\mathrm{NaOH}$ solution was determined colorimetrically at $492 \mathrm{~nm}$ by the phenol-sulfuric acid method. Both cell turbidity and the amount of WIG were used as indicators of the amount of biofilm.

\section{Acid etching of specimens}

Ti or HA was etched with $30 \%$ phosphoric acid for 3 minutes. After etching the specimens, each specimen was washed by rinsing
Table 1. Measurement of contact angles

\begin{tabular}{ccc}
\hline & HA & Ti \\
\hline Contact angle $\left(^{\circ}\right)$ & $81.6 \pm 4.98$ & $59.6 \pm 6.54$ \\
\hline
\end{tabular}

in water and was dried in a desiccator. Acid etching was performed to evaluate the acid corrosion effect of accumulated biofilm on $\mathrm{Ti}$ and HA.

\section{Scanning electron microscopy observation}

After 5 and 18 hours of biofilm formation in the AMS, each disk was rinsed thoroughly with PBS, mounted on a piece of cork and fixed with PBS containing 2.5\% glutaraldehyde ( $\mathrm{pH} 7.4)$. Following fixation, disks were dehydrated through a graded series of ethanol $(50,60,70,80,90,95$ and $100 \%)$ and then dried with tetramethylsilane. After ion coating with gold, the morphology of the cells was observed using SEM (JSM-5600LV; JEOL, Tokyo, Japan) at an accelerating voltage of $10 \mathrm{kV}$. Ti and HA before the assay and after acid etching were also observed after ion-plating under the same SEM conditions.

\section{Statistics}

Significant differences were determined by one-way analysis of variance (ANOVA) using GraphPad software (Graphpad Prism; GraphPad Software Inc., San Diego, CA, USA). Statistical significance was set at $\mathrm{p}<0.05$.

\section{Results}

Table 1 shows the results of contact angle measurements of the Ti or HA surface against water. The contact angle of the HA disk was higher than the Ti disk, indicating that the HA disk was more hydrophobic than the Ti disk.

Fig. 2 shows the amount of bacterial cells on each specimen after different assay periods (5 and 18 hours). The amount of $S$. 
(a) S. mutans

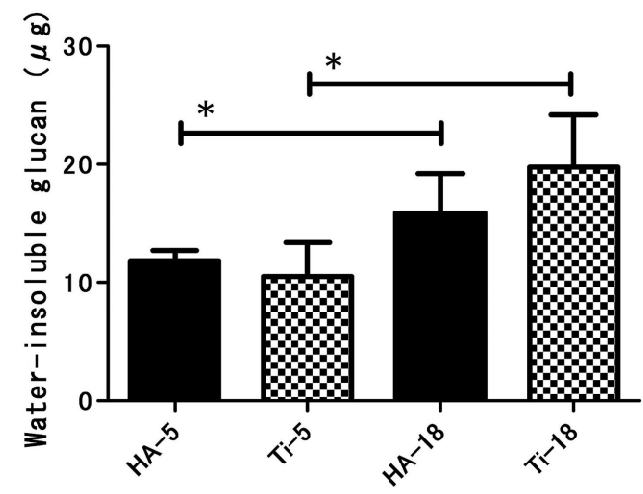

(b) S. sobrinus

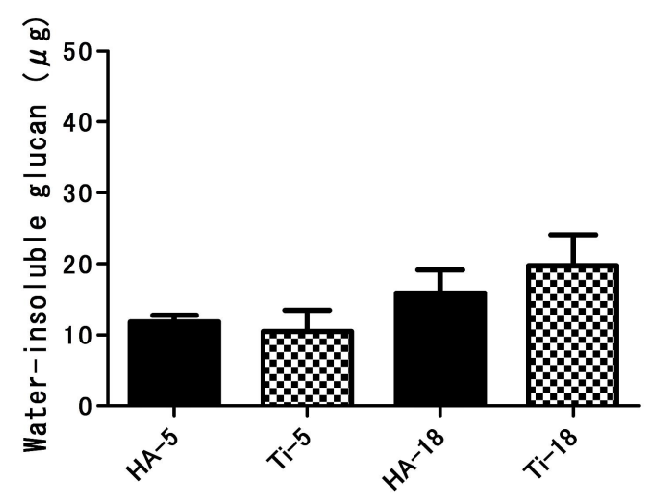

Figure 3. Amount of WIG by phenol- $\mathrm{H}_{2} \mathrm{SO}_{4}$ method. Bars represent means $\pm \mathrm{SD}, * \mathrm{P}<0.05$. a: $S$. mutans, b: $S$. sobrinus.
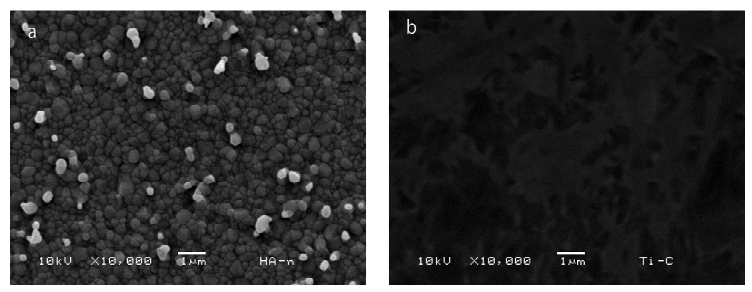

Figure 4. Results of SEM observation before assays. a: HA, b: Ti, Bars: $1 \mu \mathrm{m}$.
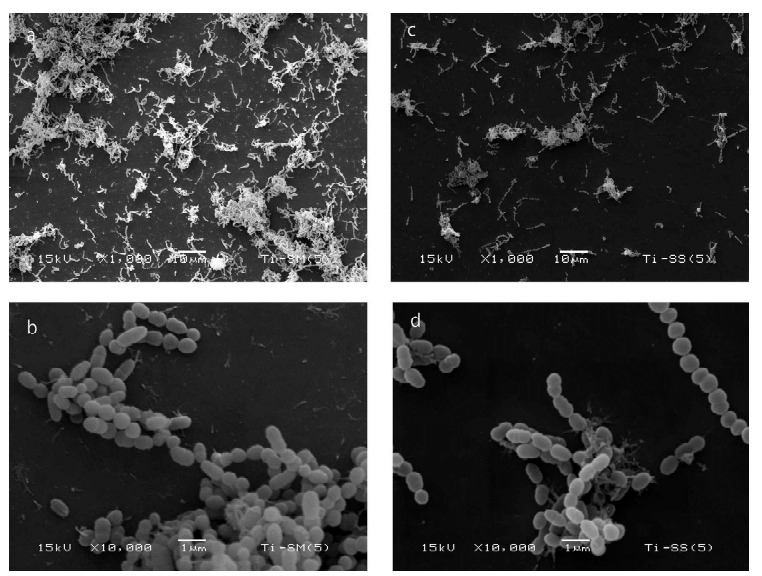

Figure 6. Results of SEM observation in Ti specimen after $5 \mathrm{~h}$. a and b: S. mutans, c and d: S. sobrinus, Bars: a and c; $10 \mu \mathrm{m}, \mathrm{b}$ and d; $1 \mu \mathrm{m}$.

mutans and S. sobrinus cells after the 18 hours assay was significantly higher than after 5 hours $(\mathrm{p}<0.05)$. No significant differences existed between Ti and HA specimens for both $S$. mutans and S. sobrinus in each assay period.

Fig. 3 shows the amount of WIG by the phenol- $\mathrm{H}_{2} \mathrm{SO}_{4}$ method. The 18 hours assay specimens provided a significantly higher amount of WIG by $S$. mutans than 5 hours specimens $(\mathrm{p}<0.05)$. There were no significant differences between Ti and HA in the amount of WIG in each assay period. In the case of S. sobrinus, the amount of WIG was not affected by the assay time. The amount of WIG did not differ between HA and Ti at each assay time, as
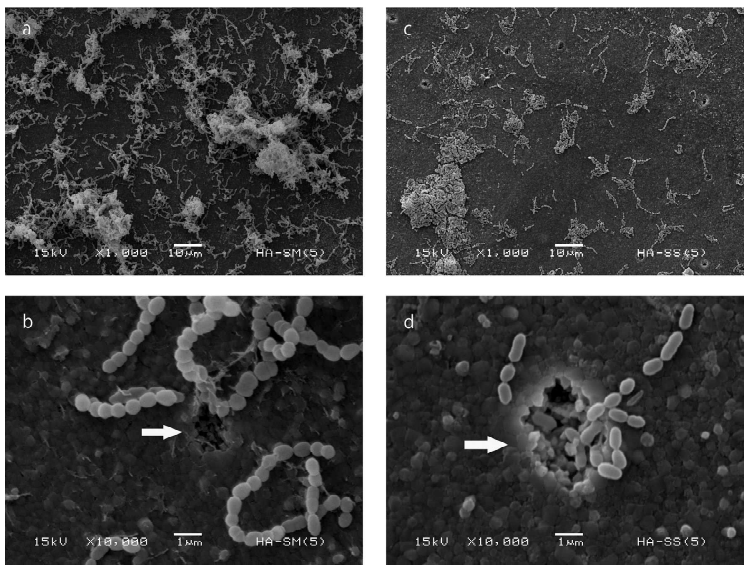

Figure 5. Results of SEM observation in HA specimen after $5 \mathrm{~h}$. White arrow: pore, a and b: S. mutans, c and d: S. sobrinus, Bars: a and c; $10 \mu \mathrm{m}, \mathrm{b}$ and $\mathrm{d} ; 1 \mu \mathrm{m}$.

shown in Fig. 3b.

The results of SEM observation of each specimen surface before the assay are shown in Fig. 4. Ti specimens had a very smooth surface. On the other hand, HA specimens showed HA graining with a diameter of approximately $0.5 \mu \mathrm{m}$.

Figure 5 shows the SEM appearance of the surface of HA specimens after 5 hours using AMS. Biofilm formation of $S$. mutants and $S$. sobrinus was recognized on the HA specimen surface, and no distinct differences were recognized between $S$. mutants and $S$. sobrinus. Higher magnification observation revealed the formation of pores with a diameter of approximately $5 \mu \mathrm{m}$. Pores were present close to or underneath the formed biofilm.

Biofilm formation of $S$. mutants and $S$. sobrinus was also clearly identified on the Ti specimen surface, as shown in Fig. 6. Similar appearances were observed between $S$. mutants and $S$. sobrinus. The Ti surface showed almost the same appearance as the HA surface. There were no pores on Ti surfaces with both $S$. mutants and S. sobrinus.

Fig. 7 shows the SEM observation of the HA surface after 18 hours. Growth of biofilm was confirmed. More aggregation of 
Eiji Yoshida et al.: Biofilm Formation using Artificial Mouth System
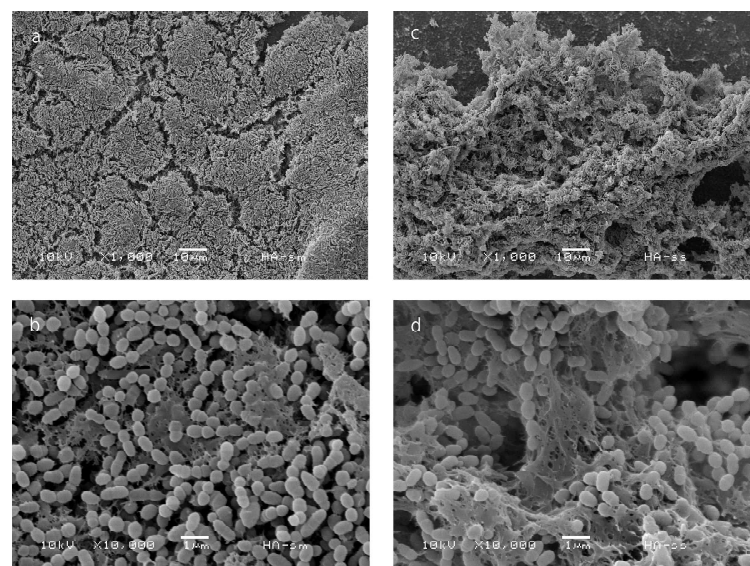

Figure 7. Results of SEM observation in HA specimen after 18h. a and b: $S$. mutans, c and d: $S$. sobrinus, Bars: a and c; $10 \mu \mathrm{m}, \mathrm{b}$ and d; $1 \mu \mathrm{m}$.
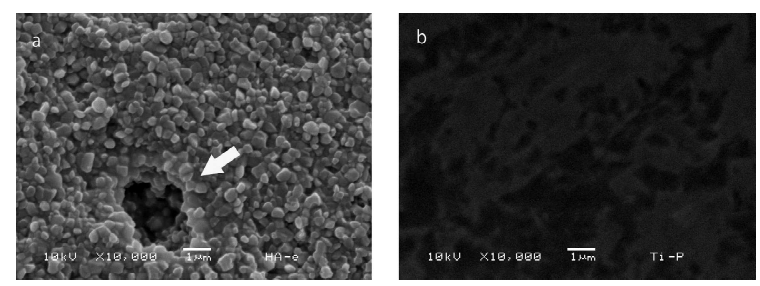

Figure 9. SEM images of HA and Ti after acid etching. White arrow: pore, a: HA, b: Ti, Bars: $1 \mu \mathrm{m}$.

bacterial cells was observed. Detachment of the biofilm of $S$. sobrinus could be partly observed. Pores could not be identified due to the over-layering formation of biofilm.

Fig. 8 shows the SEM appearances of the Ti surface after 18 hours. Growth of biofilm was also observed. In the case of $S$. sobrinus, most of the aggregated biofilm detached from the $\mathrm{Ti}$ surface during sample preparation, especially the dehydration procedure. Thus, less aggregation of biofilm was observed for $S$. sobrinus.

Fig. 9 shows SEM images of HA and Ti after acid etching. Pores are observed on the HA surface, but not on the Ti surface.

\section{Discussion}

HA and Ti are now widely used as bone substitute materials or dental implant materials. However, there are few reports of biofilm formation on HA or Ti. Thus, in the present study, the biofilm formation of $S$. mutans and $S$. sobrinus on hydroxyxapatite or Ti was evaluated using an AMS.

The AMS simulates the complex oral environment and provides a continuous or intermittent supply of nutrients to bacterial plaque or biofilm. Among the various kinds of AMSs, our AMS was originally developed by Hinode et al. ${ }^{4)}$ in 1984. The aim of this system is to assess the important parameters responsible for causing dental caries, such as biofilm formation, the $\mathrm{pH}$ underneath biofilm and enamel demineralization. Usui et
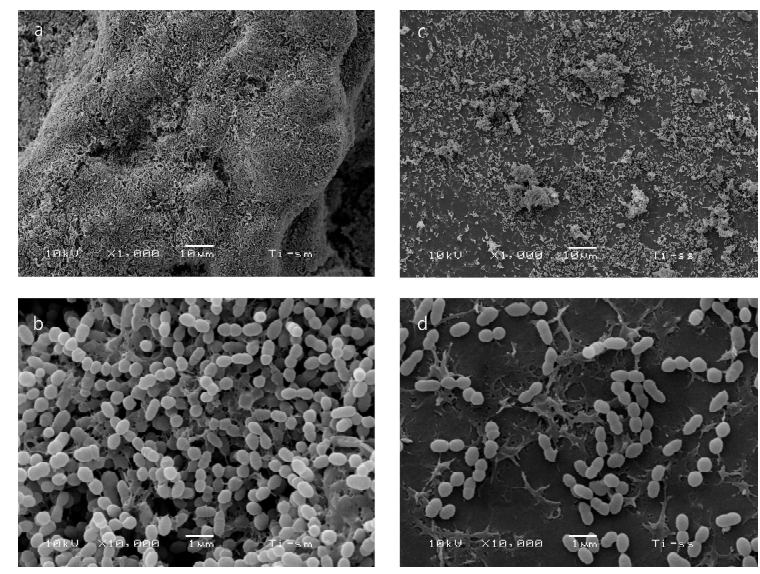

Figure 8. Results of SEM observation in Ti specimen after 18h. a and b: S. mutans, c and d: S. sobrinus, Bars: a and c; $10 \mu \mathrm{m}, \mathrm{b}$ and d; $1 \mu \mathrm{m}$

al. reported that diammine silver fluoride had a strong anticarcinogenic effect on dentin using the present $\mathrm{AMS}^{10)}$. Kamoda et al. ${ }^{11)}$ reported that dissacharide xylosylfructoside partly inhibited the cariogenicity of sucrose using the AMS. They also showed good reproducibility of the $\mathrm{pH}$ curves. Effect of bovine lactoferrin on enamel demineralization and acid fermentation was also evaluated using $\mathrm{AMS}^{12)}$. These results suggested that the present AMS is reliable as an in vitro system.

The amount of bacterial cells and the amount of WIG were detected and there were no distinct differences in biofilm formation between HA and Ti. It is widely known that WIG, which is produced by glucosyltransferase of bacteria, plays a significant role in the adhesion of biofilm to substances ${ }^{13,14)}$. On SEM observation, easy detachment of $S$. sobrinus biofilm was recognized during the preparation of SEM samples, as mentioned above. It is presumed that the adhesion of the biofilm of $S$. sobrinus to HA and Ti is lower than that of S. mutans.

Among the numerous factors affecting biofilm formation, surface roughness has been regarded as one of the most important factors. Many studies have reported that a rougher surface resulted in the increased adhesion of bacteria ${ }^{15-17)}$. Ikeda et al. ${ }^{7)}$ reported that a smooth resin composite surface with lower surface roughness has less bacterial adhesion than a rougher specimen surface using AMS. Surface hydrophobicity is also another factor that will influence biofilm formation ${ }^{18)}$. However, in the present study no distinct differences were identified in biofilm formation despite the differences in surface roughness and hydrophobicity, which were determined by contact angles, between HA and Ti. To clarify the mechanism of biofilm formation, the conditions of AMS employed in the present study, such as flow rate and sucrose concentration etc., will be investigated further.

Pore formation was observed on HA. This was due to the $\mathrm{pH}$ decrease during biofilm formation. Ti could not be influenced by the decrease of $\mathrm{pH}$. This was confirmed by acid etching of HA 
and Ti. Pores were also formed by acid etching of enamel but not Ti. It is suggested that the formation of such pores is related with caries formation. The details will be investigated further.

In conclusion, biofilm formation on $\mathrm{HA}$ and $\mathrm{Ti}$ could be monitored using AMS. Study of the mechanism of biofilm formation and/or the difference in biofilm components is needed using AMS.

\section{Acknowledgements}

This study was supported in part by Grants-in-Aid for Young Scientists (B) (25861902) and Scientific Research (B) (23390453) from the Japan Society for the Promotion of Science, and project grants from the society for Tsurumi University School of Dental Medicine. The authors declare no conflicts of interest.

\section{References}

1. Auschill TM, Arweiler NB, Brecx M, Reich E, Sculean A and Netuschil L. The effect of dental restorative materials on dental biofilm. Eur J Oral Sci 110: 48-53, 2002

2. Subramani K, Jung RE, Molenberg A and Hammerle CH. Int J Oral Maxillofac Implants 24: 616-626, 2009

3. Busscher HJ, Rinastiti M, Siswomihardjo $\mathrm{W}$ and van der Mei HC. Biofilm formation on dental restorative and implant materials. J Dent Res 89: 657-665, 2010

4. Hinode $\mathrm{M}$, Imai $\mathrm{S}$ and Nisizawa T. New artificial mouth for evaluation of plaque accumulation, $\mathrm{pH}$ changes underneath the plaque, and enamel demineralization. Jpn J Oral Biol 28: 288-291, 1984

5. Tang G, Yip HK, Cutress TW and Samaranayake LP. Artificial mouth model systems and their contribution to caries research: a review. J Dent. 31: 161-71, 2003

6. Ono M, Nikaido T, Ikeda M, Imai S, Hanada N, Tagami J and Matin K. Surface properties of resin composite materials relative to biofilm formation. Dent Mater J. 26: 613-622, 2007

7. Ikeda M, Matin K, Nikaido T, Foxton RM and Tagami J. Effect of surface characteristics on adherence of $S$. mutans biofilms to indirect resin composites. Dent Mater J. 26: 915-
923, 2007

8. Hayati F, Okada A, Kitasako Y, Tagami J and Matin K. An artificial biofilm induced secondary caries model for in vitro studies. Aust Dent J. 56: 40-47, 2011

9. Bowden GHW and Li YH. Nutritional influences on biofilm development. Adv Dent Res. 11: 81-99, 1997

10. Usui Y, Imai S, Saito N, Hanada N and Uematsu H. Effect of $3.8 \% \mathrm{Ag}\left(\mathrm{NH}_{3}\right)_{2} \mathrm{~F}$ solution as an anti-caries agent on dentin in artificial mouth model system using an actinomyces neaslundii. J Dent Hlth 55: 186-193, 2005

11. Kamoda $T$, Imai $T$, Sao $T$, Imai $S$, Nishizawa $T$ and Hanada N. Effect of dissacharide xylosylfructoside on sucrose cariogenicity in an artificial mouth system. J Dent Hlth 56: 281-288, 2006

12. Kaeriyama E, Imai S, Usui Y, Hanada $\mathrm{N}$ and Takagi Y. Effect of bovine lactoferrin on enamel demineralization and acid fermentation by Streptococcus mutans. Pediatric Dentanl Journal 17: 118-126, 2007

13. Banas J A, and M M Vickerman. Glucan-binding proteins of the oral streptococci. Crit Rev Oral Biol Med. 14: 89-99, 2003

14. Bowen W H, and H Koo. Biology of streptococcus mutansderived glucosyltransferases: role in extracellular matrix formation of cariogenic biofilms. Caries Res. 45: 69-86, 2011

15. Teughels W, Van Assche N, Sliepen I and Quirynen M. Effect of material characteristics and/or surface topography on biofilm development. Clin Oral Implants Res. 17: 68-81, 2006

16. Lee BC, Jung GY, Kim DJ and Han JS. Initial bacterial adhesion on resin, titanium and zirconia in vitro. $\mathrm{J}$ Adv Prosthodont. 3:81-84, 2011

17. Subramani K, Jung RE, Molenberg A and Hammerle CH. Biofilm on dental implants: a review of the literature. Int J Oral Maxillofac Implants. 24: 616-626, 2009

18. Quirynen M and Bollen CM. The influence of surface roughness and surface-free energy on supra- and subgingival plaque formation in man. A review of the literature. J Clin Periodontol. 22: 1-14, 1995 